\title{
High-frequency boundary layer profiling with reusable radiosondes
}

\author{
D. Legain ${ }^{1}$, O. Bousquet ${ }^{1,2}$, T. Douffet ${ }^{1}$, D. Tzanos $^{1}$, E. Moulin ${ }^{1}$, J. Barrie ${ }^{1}$, and J.-B. Renard ${ }^{3}$ \\ ${ }^{1}$ CNRM-GAME, UMR3589, Météo-France/CNRS, Toulouse, France \\ ${ }^{2}$ LACy, UMR8105, Météo-France/CNRS/Université de La Réunion, St-Denis de La Réunion, France \\ ${ }^{3}$ LPC2E-CNRS/Université d'Orléans, Orléans, France
}

Correspondence to: O. Bousquet (olivier.bousquet@meteo.fr)

Received: 15 March 2013 - Published in Atmos. Meas. Tech. Discuss.: 9 April 2013

Revised: 13 July 2013 - Accepted: 18 July 2013 - Published: 29 August 2013

\begin{abstract}
A new system for high-frequency boundary layer profiling based upon radiosondes and free balloons was tested during the field phases of the Boundary Layer Late Afternoon and Sunset Turbulence experiment (BLLAST 2011, Lannemezan, France) and of the Hydrological cycle in the Mediterranean Experiment (HyMeX, 2012). The system consists of a conventional Vaisala receiver and a GPS radiosonde (pressure, wind, humidity and temperature), that is tied to a couple of inflated balloons. The principle of the sounding system is to permit the first balloon to detach from the rawinsonde at a predetermined altitude, allowing for the rawinsonde to slowly descend with the second balloon to perform a second, new sounding. The instrumentation is then eventually recovered. The expecting landing area is anticipated before the flight by estimating the trajectory of the probe from a forecasted wind profile and by specifying both the balloon release altitude and the mean ascent and descent rates of the system. The real landing point is determined by the last transmission of the radiosonde GPS and the visual landmark provided by the second balloon. Seventytwo soundings were performed during BLLAST (62) and $\operatorname{HyMeX}(10)$, with a recovery rate of more than $80 \%$ during the BLLAST field campaign. Recovered radiosondes were generally reused several times, often immediately after recovery, which definitely demonstrates the high potential of this system.
\end{abstract}

\section{Introduction}

The observation of meteorological parameters through the depth of the atmosphere can be achieved by remote sensing (e.g. radars, lidars, sodars, radiometers) or through in situ measurements made by aircraft or sounding balloons. The latter are commonly used in meteorology to collect humidity, temperature and wind data, as well as any other parameters that can be inferred from inexpensive, expendable instrumentation such as radiosondes. Free sounding balloons can collect high-resolution observations throughout the troposphere in all weather conditions, and are often used to achieve reference measurements for weather forecast, data assimilation or remote sensing technique validation.

When the required measurement frequency becomes too high, or when the meteorological sensors are expensive (e.g. ozone, turbulence or aerosol sensors), free sounding balloons become economically impractical, and are often replaced by tethered balloons, which allow for recovery of the meteorological instrumentation. Tethered balloons nevertheless suffer from important limitations (e.g. flight clearance, limited payload and limited range of measurement), and cannot be used in all weather conditions unlike free balloons.

The purpose of this paper is to present a sounding system that would account for both the flexibility of the free balloons and the ability to recover instrumentation from tethered balloons. The proposed development is based upon the pioneering research of Albert the 1st of Monaco, who developed a two-balloon system to perform soundings at sea on the ship Princesse Alice (Mesinger, 1921) in the early twentieth century. By charting the course of the ship and using a theodolite, the crew was able to ascertain the point where the instrumentation would reach the sea so as to recover the 


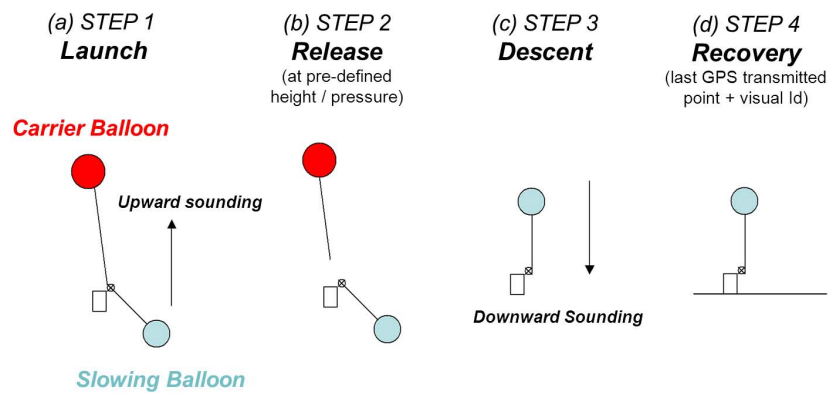

Fig. 1. Principle of the dual-balloon sounding.

data recorder. Other systems for the recovery of meteorological sensors have been proposed later by Tennermann et al. (2004), using a tethered balloon, and Douglas (2008), using a light-weight, motorized glider programmed to return to the launch site. The cost of the latter systems, however, makes their dissemination complicated, and represents an important challenge that has yet to be solved.

The two-balloon system described in this study is a lowcost device that is designed to be easily implemented on any available free balloon sounding system to measure all physico-chemical parameters for which sufficiently light instrumentation exists. It was first tested in 2011 in calm, clear air conditions within the frame of the Boundary Layer Late Afternoon and Sunset Turbulence (BLLAST) field experiment (Lothon et al., 2012) before being later evaluated in a more hostile environment during the 2012 field phase of the Hydrological cycle in the Mediterranean Experiment (HyMeX, Ducrocq et al., 2013).

The principle, components, cost effectiveness and potential applications of the dual-balloon sounding system are described in Sect. 2. A first evaluation of the system performance is presented in Sect. 3 using the 62 launches performed during the BLLAST experiment. Finally, Sect. 4 gives some examples of soundings performed during the HyMeX field phase, and discusses the potential of this device for recovering prototype or expensive probes.

\section{Sounding principle}

\subsection{Overview of the system}

The principle of the two-balloon radiosounding system is shown in Fig. 1. It consists of sending aloft a couple of differently inflated balloons (referred to as the "carrier" and "slowing" balloons) in tandem in order to lift up the instrumentation and perform an upward sounding (Fig. 1a). Both balloons are inflated using tares so as to set the vertical ascent/descent rates of the whole system to known preset values. The carrier balloon is tied to the rawinsonde by a wire and linked to a separation system programmed to trigger at a preset atmospheric pressure that is specified before the

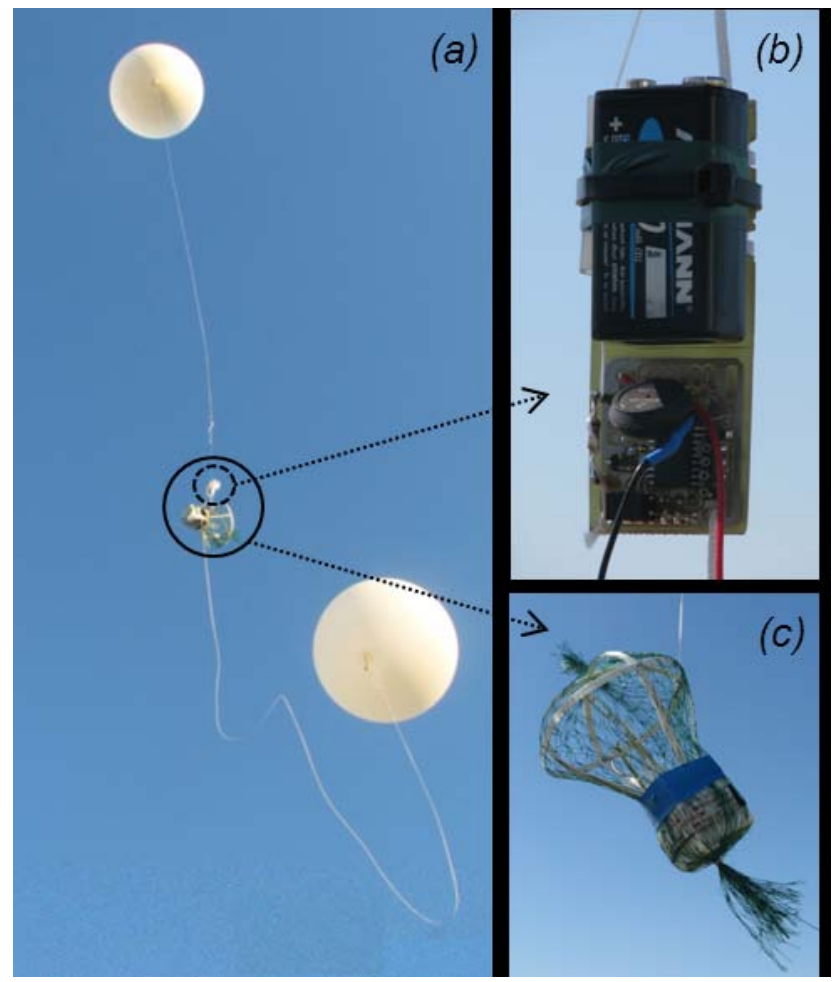

Fig. 2. Overview of the dual-balloon sounding system: (a) complete system, (b) separation device and (c) radiosonde protection system.

launch (Fig. 1b). The point of attachment for both the carrier and the slowing balloons is the same, which in turn is identical to that of a classical sounding. The value of the bending angle recommended by radiosonde manufacturers can thus be maintained during the descent.

Once the carrier balloon has been released, the instrumentation descends with the slowing balloon to perform a downward sounding (Fig. 1c). When the probe has reached the ground (Fig. 1d), the buoyancy of the slowing balloon becomes positive. The balloon can then be used as a landmark to determine more easily the landing point and to recover the probe.

The different components of the system are shown in Fig. 2. It is composed of the carrier and slowing balloons (Fig. 2a), a meteorological radiosonde with a GPS probe for wind measurement and positioning (Fig. 2b), a separation device tied to the carrier balloon (Fig. 2c) and a ground receiver station.

In order to be reused, the instrumentation is protected against possible damage arising from contact with the ground and vegetation. The protection (Fig. 2c) consists in a $15 \mathrm{~cm}$ diameter sphere encompassing the radiosonde that was designed to minimize the disruption of the flow around the sensors. It is made of a plastic net wrapped around thin strips of rigid plastic $(6 \mathrm{~mm} \times 1 \mathrm{~mm}, \mathrm{ABS})$. The potential impact of this protection on measurements was estimated at ground 
level through comparisons between a regular and a protected radiosonde, with $850 \mathrm{~W} \mathrm{~m}^{-2}$ incoming solar radiation and $3.5 \mathrm{~m} \mathrm{~s}^{-1}$ wind speed. Each probe was used alternately with and without the protection to take into account a possible bias between the two radiosondes. The temperature difference was lower than $0.1^{\circ} \mathrm{C}$, and no difference could be detected in relative humidity measurements.

The release of the carrier balloon is performed by cutting the wire that ties the balloon to the probe. The light-weight separation device was laboratory tested down to a temperature of $-20^{\circ} \mathrm{C}$. It is composed of both a Microchip microcontroller PIC 16F88 and a Freescale MPX4515A analogue pressure sensor that performs measurements in the range $1150-150 \mathrm{hPa}$ with an accuracy of $15 \mathrm{hPa}$. Raw pressure data are collected by rounds of nine measurements performed every $100 \mathrm{~ms}$. The separation order is based upon the median value of those nine samples to mitigate the impact of noisy measurements. The set release is coded on 6 bits, which provides a resolution of $10 \mathrm{hPa}$ between 1050 and $420 \mathrm{hPa}$. The separation is achieved by fusion of a nylon wire wrapped around a resistance of $15 \Omega, 1 / 4 \mathrm{~W}$ powered at $8.2 \mathrm{~V}$. The mean delay between the pressure measured by the sensor and the target separation is $3 \mathrm{hPa}$ ( $\mathrm{STD}$ of $2 \mathrm{hPa}$ ).

The release of the carrier balloon can be also achieved by mechanical or pyrotechnical means depending on sounding conditions, and can potentially be triggered by a timer or a pressure sensor.

\subsection{Balloon inflation and launching}

Ascending and descending speeds must be known as accurately as possible in order to properly estimate the landing area of the probe. Furthermore, commercial probe measurements are only valid for a given speed range (to properly compensate the effect of radiation on the temperature sensors, for example). The balloon inflation is thus completed to achieve two objectives: a known diameter to adjust the speed of ascent/descent, and a sufficient buoyancy to ensure both the lift of the slowing balloon and its visibility from a distance once the probe has reached the ground. Balloons are inflated using tares. The carrier (slowing) balloon is a $300 \mathrm{~g}$ $(100 \mathrm{~g})$ Totex latex balloon. In our case, the rate of descent is limited by a compromise between the descent speed (ideally $5 \mathrm{~m} \mathrm{~s}^{-1}$ to ensure a correct ventilation of the probes) and the lift of the balloon at the ground to mark the landing point. A descending speed of $3.4 \mathrm{~m} \mathrm{~s}^{-1}$ was obtained through experimentation and proved to be a good compromise.

\subsection{Flight simulation software}

Dedicated software has been developed to forecast balloon trajectories and estimate the landing point of the probe. The anticipated location is determined by calculating the most probable trajectory of the balloons (Fig. 3) based on (i) a forecasted (or measured) vertical profile of horizontal wind

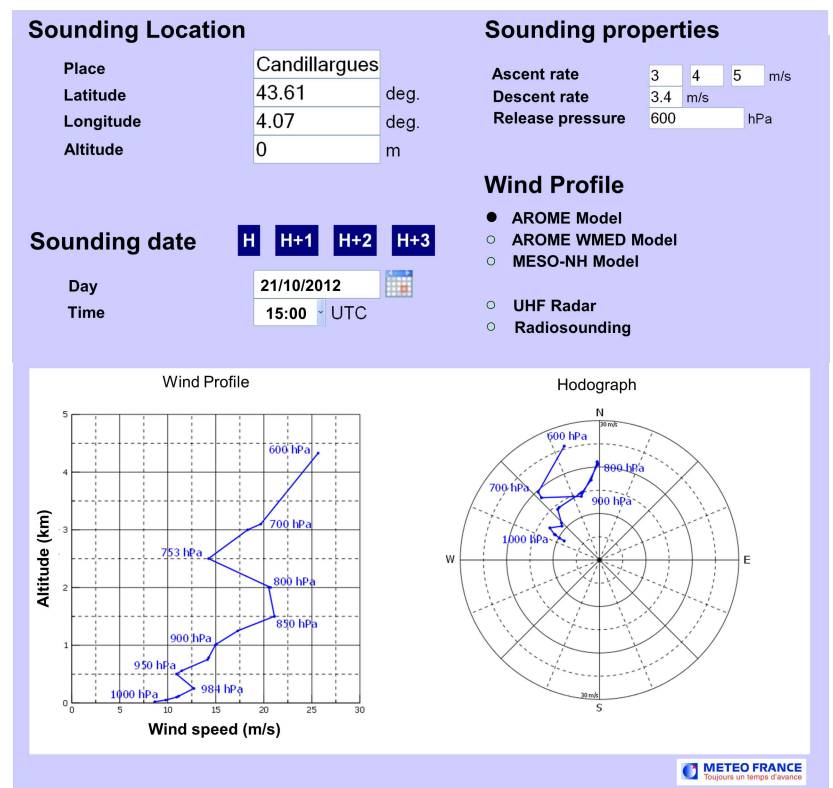

Fig. 3. Interface of the flight simulation software. Displayed wind data are used to simulate the flight trajectories shown in Fig. 5.

at the launching site, (ii) hypotheses on both the ascending/descending speed of the system, and (iii) the chosen release pressure of the carrier balloon. In the current version one can use a wind profile derived from wind profiler measurements, numerical weather prediction model forecast or radiosounding data, but all sources of wind profiles can potentially be assimilated in this easily portable software. Performing flight trajectory simulations before the launch allows for mitigating the risk of having the probe fall in areas difficult to access (e.g. water, urban areas, forests), as well as to allow for the recovery team to reposition quickly after the radiosonde has landed. Performing balloon trajectory simulations also allows for the system to be set up so as to sample a specific area or to accomplish a particular objective. Examples of applications that would require a precise setting of the system are shown in Fig. 4. This includes modification of boundary layer properties by a surface transition (Fig. 4a), measurement on each side of a drastic change in terrain/topography (Fig. 4b) or observation of coastal breezes (Fig. 4c), but many other applications could be envisioned. In each of the case scenarios shown in Fig. 4, the distance travelled by the radiosonde must be known as accurately as possible in order to attain the scientific objective of the sounding. One way to do so is to play with the release height or with the ascent/descent rate of system, which is controlled by the volume of the balloons.

An example of flight trajectory simulation is shown in Fig. 5. In this example, the objective is to describe the possible modifications experienced by an oceanic air mass during its propagation from the coast to the foothills of the Massif Central (black dashed line), located $\sim 40 \mathrm{~km}$ north of the 


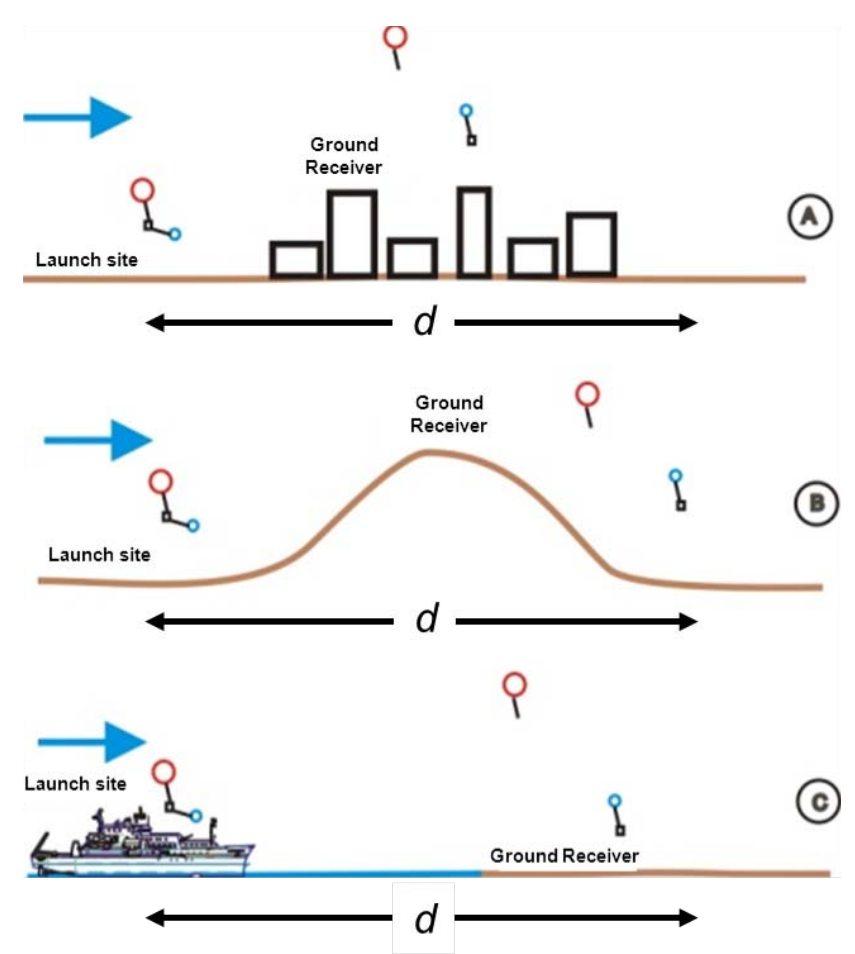

Fig. 4. Example of applications of the dual-balloon sounding system: (a) modification of boundary layer properties by a surface transition, (b) measurement on each side of a mountain and (c) observation of coastal breezes. Distance $d$ indicates the distance that must be travelled by the radiosonde in order to achieve the objective. In (a)-(b), the receiver is not operated at the launch site in order to have a good radio reception on each side of the town or of the mountain. In (c), the "ground" receiver can be operated either on the boat or at the ground.

launch site. The wind profile at the launch site that is used to estimate the flight trajectory is shown in Fig. 3. It is derived from a numerical forecast of the operational model Arome (Seity et al., 2011), valid on 21 October 2012 at 15:00 UTC. In this flight simulation, the slowing balloon is inflated so as to achieve a mean descent rate of $3.4 \mathrm{~m} \mathrm{~s}^{-1}$, and the release pressure of the carrier balloon is set to $600 \mathrm{hPa}(\sim 4200 \mathrm{~m})$. The trajectories shown in Fig. 5 correspond to various ascent speed hypotheses ranging from 3 to $5 \mathrm{~m} \mathrm{~s}^{-1}$. According to the simulated trajectories, the carrier balloon would have to be inflated so as to reach a mean ascent rate of 4 to $5 \mathrm{~m} \mathrm{~s}^{-1}$ for the radiosonde to land near the foothills. Using a slower ascent speed would likely result in a greater travelled distance, and the radiosonde would possibly fall over the terrain.

Overall, using this system allows for more precision and control than that offered by a regular radiosonde equipped with a parachute. Indeed, the burst altitude of a meteorological balloon depends mainly of its properties and the way it is inflated. For a given type of balloon, the uncertainty on the burst altitude is generally high, and the burst level is particularly difficult to adjust for altitudes below $4000 \mathrm{~m}$, such

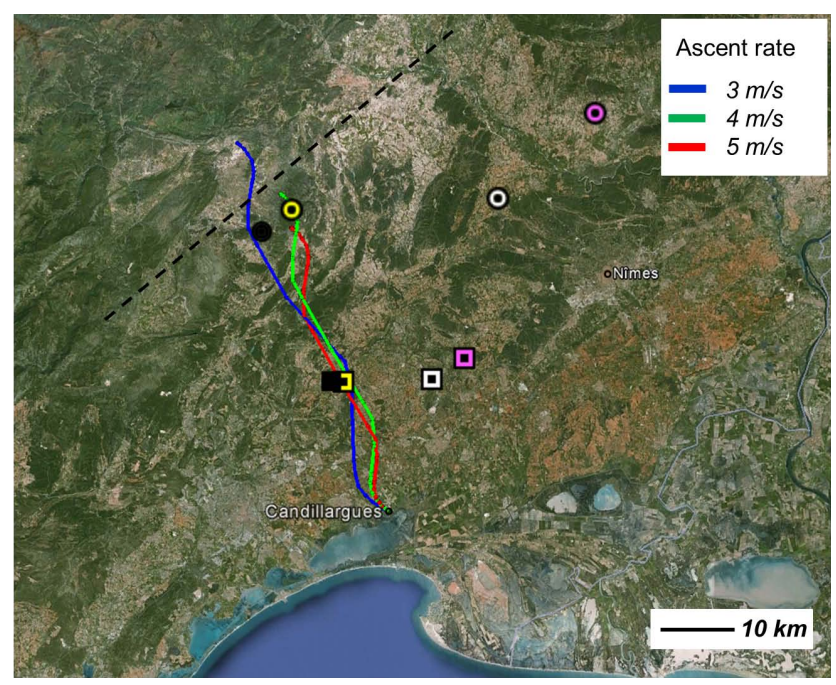

Fig. 5. Flight trajectory simulations valid 21 October 2012 at 15:00 UTC, according to the wind profile and sounding settings displayed in Fig. 3. The launch site is located in Candillargues, along the Mediterranean coast. Blue, green and red trajectories correspond to flight simulations made from mean ascent rates of 3,4 and $5 \mathrm{~m} \mathrm{~s}^{-1}$, respectively. The yellow circle (square) indicates the actual landing point (separation point) of the radiosonde. Other circles/squares show the actual landing (separation point) of soundings performed at 10:50 UTC, 21 October 2012 (black), 09:03 UTC, 17 October 2012 (white) and 11:55 UTC, 17 October 2012 (pink). The foothills of the Massif Central mountains are indicated by the dashed black line.

as those generally targeted with the new system. The more accurate control of the separation altitude also allows for reduction of the uncertainty in the landing point of the probe, and thus improves the odds to recover the sensor. The descent rate achieved with the two-balloon sounding device is moreover significantly slower than that of a radiosonde equipped with a parachute, which allows for a better measurement resolution in the vertical.

\subsection{Probe recovery}

The instrumentation is recovered from the last known position recorded during the descent of the balloon. In cases where the last received position does not match the ground, the landing point is extrapolated from the last wind measurement provided by the sonde. Ultimately, a label on the probe provides information allowing for the possibility of members of the public to contact operators.

\subsection{Cost effectiveness}

The implementation of the dual-balloon sounding system generates extra costs, which can be separated into two components: expenses resulting from the modification of the original radiosounding system, and costs associated with in 
situ implementation. The modification of the system costs approximately $€ 40$ - this includes the second balloon, the separation device and the probe protection - and requires about $1 \mathrm{~h}$ of work. Its implementation in the field requires about 30 extra minutes to inflate the second balloon in order to check the radiosonde, to perform the flight simulations and to program the separation device. The extra labour cost to recover the radiosonde obviously depends on both the distance travelled by the radiosonde and weather conditions, but it can be roughly estimated to about $45 \mathrm{~min}$ to one hour per sounding. Overall, the cost effectiveness increases with the frequency of the soundings and the value of the instrumentation. If the launch and landing sites are far apart and the sounding frequency is low, the value of the recovery may be somewhat reduced, especially if one plans just to perform a classical radiosounding (emphasis should thus be put primarily on scientific objectives such as those shown in Fig. 4). If the sounding frequency is high or if the instrumentation is expensive, then cost effectiveness would be very high.

\section{Test of the system during BLLAST}

\subsection{The BLLAST experiment}

The 3-week field phase of the Boundary Layer Late Afternoon and Sunset Turbulence (BLLAST) experiment was conducted in the summer of 2011 in Lannemezan, in the French Pyrenees (Lothon et al., 2012). The overall objective of BLLAST was to collect accurate observations of the so-called late-afternoon transition (LAT), which corresponds to the period when the convective boundary layer decays to an intermittently turbulent residual layer overlying a stably stratified boundary layer. The objective of BLLAST was to better understand the physical processes that control the LAT, and to elucidate its role on both mesoscale and turbulencescale motions. This campaign brought together many complementary observation devices including unmanned aerial vehicles (UAV), aircraft, wind profilers, sodar, lidars, tethered balloons and balloon soundings, among others, with the objective of achieving an exhaustive description of the dynamical processes in the boundary layer.

\subsection{BLLAST sounding summary}

The new high-frequency sounding device was tested with conventional Vaisala radiosondes (RS-92) during nine intensive observation period (IOP) days. A team of four people was in charge of conducting high-frequency sounding activities. As soon as the radiosonde was in the air, two of the people involved in the sounding preparation had to leave the launch site to recover the probe. Soundings were performed on an hourly basis from 12:00 to 21:00 UTC with the objective of capturing the evolution of the planetary boundary layer (PBL) during the LAT. The carrier balloon separation was set to occur below the cloud base (average (a) Potential Temperature (K)

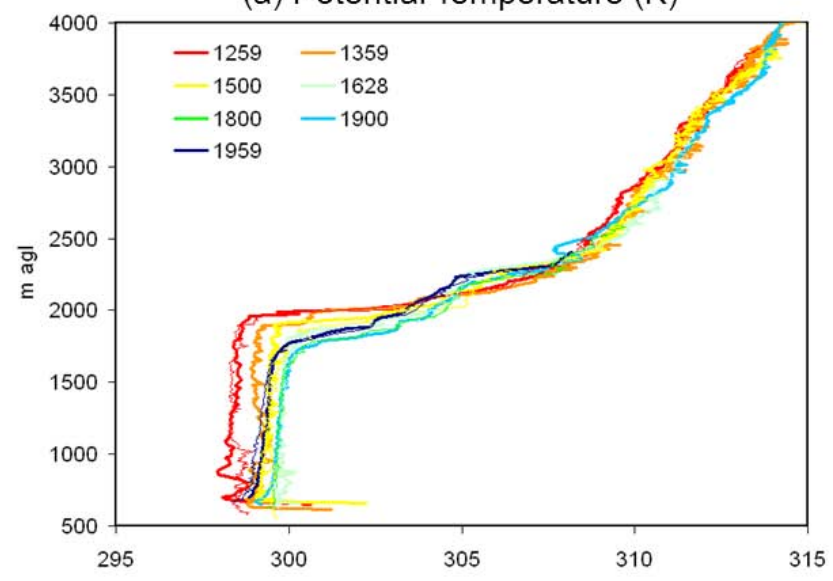

(b) Mixing ratio $(\mathrm{g} / \mathrm{kg})$

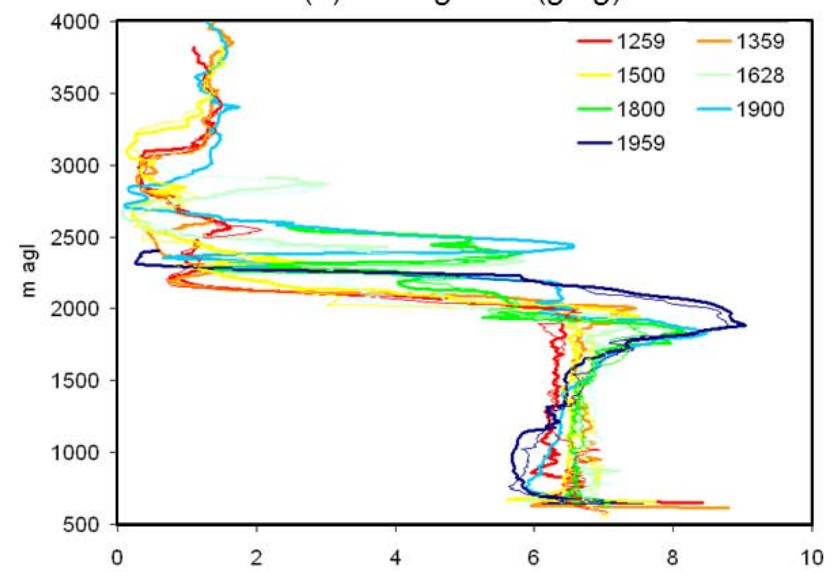

Fig. 6. Time series of hourly soundings performed on 1 July 2011 between 13:00 and 20:00 UTC. (a) Potential temperature (K) and (b) water vapour mixing ratio $\left(\mathrm{g} \mathrm{kg}^{-1}\right)$. Bold and thin lines correspond to ascending and descending soundings, respectively.

$2700 \mathrm{~m}, \min / \mathrm{max} 1100 \mathrm{~m} / 4500 \mathrm{~m}$ ), but high enough to sample the whole boundary layer. The original rawinsonde batteries were replaced with accumulators. The total weight of the modified rawinsonde (release mechanism + probe + accumulators) was $\sim 265 \mathrm{~g}$, which is slightly less than the weight of the original probe $(274 \mathrm{~g})$. As stated previously, all carrier (slowing) balloons were inflated to achieve an ascent (descent) rate of $\sim 5(3.4) \mathrm{m} \mathrm{s}^{-1}$. Landing points were predicted using vertical wind profiles forecasted by MétéoFrance high-resolution operational model AROME.

An example of sounding time series is shown in Fig. 6, which presents the vertical structure of the PBL between 13:00 and 20:00 UTC on 1 July 2011. Seven launches were performed within this seven hour period, which allowed for collection of 14 boundary layer profiles. The first four launches were made before sunset, while the PBL was still unstable. The air temperature close to the ground was quite warm, as shown by the existence of a super-adiabatic surface 
Table 1. Sounding statistics during BLLAST.

\begin{tabular}{|c|c|c|}
\hline \# Probes available & & 20 \\
\hline \# Launches & & 62 \\
\hline Spotted probes & 53 & $(85 \%)$ \\
\hline Recovered probes & 49 & $(79 \%)$ \\
\hline Unrecovered probes ${ }^{1}$ & 4 & $(06 \%)$ \\
\hline Lost probes & 9 & $(15 \%)$ \\
\hline Reused probes & 49 & $(79 \%)$ \\
\hline True release & 46 & $(74 \%)$ \\
\hline Faulty release $^{2}$ & 6 & $(10 \%)$ \\
\hline No release & 10 & $(16 \%)$ \\
\hline
\end{tabular}

layer between 13:00 and 17:00 UTC. According to observations, the air mass near the surface becomes stable near 18:00 UTC, but cooling continued to increase over the next few hours. The maximum depth of the PBL was observed at 13:00 UTC. As time passes, the top of the boundary layer progressively decreased from $1500 \mathrm{~m}$ a.g.l. at 13:00 UTC to $1200 \mathrm{~m}$ a.g.l. at 19:00 UTC. A strong capping inversion could be observed at all times. The variation of temperature and humidity across the inversion was of the order of $6 \mathrm{~K}$ (Fig. 6a) and $6 \mathrm{~g} \mathrm{~kg}^{-1}$ (Fig. 6b), respectively. Overall, one can note that differences between ascending and descending profiles are generally not significant. This lack of variability is an interesting result that indicates the slow temporal evolution of the PBL on this particular day. Four probes were needed to complete this time series. One of them was lost and the three others were reused later in the experiment.

\subsection{Sounding statistics}

Twenty radiosondes were available for the BLLAST project, which allowed for 62 launches to be performed for a total of 114 measured vertical profiles (10 radiosondes were lost due to a failure of the separation device). Due to the weather conditions and objective of the campaign, soundings were always made over short distances. Hence, the mean horizontal distance travelled by the radiosonde was $7.36 \mathrm{~km}(\mathrm{~min} / \mathrm{max}$ $0.160 \mathrm{~km} / 11.61 \mathrm{~km})$.

Sounding statistics are presented in Table 1 . The release mechanism performed well about $84 \%$ of the time, although separation sometimes occurred at an incorrect level. The total release failure rate, which corresponds to situations where the release did not occur or occurred at the wrong pressure, reached $16 \%$. Eighty-five percent of the released probes were visually identified within $1 \mathrm{~h}$ after landing. Among those, $79 \%$ were recovered and reused at least one time, sometimes immediately after recovery. Considering that 11 probes were still available at the end of the experiment, only 9 probes were thus needed to perform 114 vertical soundings of the atmosphere. Also note that five probes were sent back to the project thanks to contact information provided on the probes (those probes are, however, considered as lost in the statistics).

\subsection{Uncertainties on the landing point}

As discussed earlier, a proper estimation of the landing point is needed to maximize the odds of recovering the probes or to achieve particular applications (Fig. 4). The two major sources of uncertainties arise from the estimation of the ascent/descent speed of the system and from the accuracy of the vertical wind profile used to estimate the flight trajectory. A couple of experiments were conducted from the BLLAST dataset in order to evaluate the impact of these errors on the determination of the landing point. Figure $7 \mathrm{a}$ shows the differences between the actual landing point of each recovered radiosonde and the ones simulated using horizontal wind profiles forecasted by Arome at the time of soundings and (i) mean theoretical ascent and descent speeds of 5 and $3.4 \mathrm{~m} \mathrm{~s}^{-1}$ (red), respectively, or (ii) mean vertical speeds derived from in situ radiosonde measurements (black) - the actual mean descent speed computed from 49 soundings is $3.55 \mathrm{~m} \mathrm{~s}^{-1}$ (STD $0.86 \mathrm{~m} \mathrm{~s}^{-1}$ ), while the mean ascent speed is $5.35 \mathrm{~m} \mathrm{~s}^{-1}$ (STD $0.65 \mathrm{~m} \mathrm{~s}^{-1}$ ).

Overall, the dependence of the error on ascent and descent rates is relatively weak, and using true mean vertical speeds does not significantly improve the results. The position error averages around $1.57 \mathrm{~km}$ in both cases (if one considers an average flight distance of $7.36 \mathrm{~km}$ during BLLAST, this means that the actual distance travelled by the system is $22 \%$ lesser or greater than that expected). This suggests that the main source of uncertainty is more likely related to the accuracy of the horizontal wind profile used to perform the trajectory simulations.

In a second step, one can try to evaluate the impact of the accuracy of the horizontal wind profile used for flight trajectory simulations. For this purpose, theoretical trajectories of each recovered probe are simulated using theoretical mean ascent and descent speeds of $5 \mathrm{~m} \mathrm{~s}^{-1}$ and $3.4 \mathrm{~m} \mathrm{~s}^{-1}$ and (i) true horizontal wind speeds (as measured by the radiosonde), (ii) a wind profile measured by a UHF profiler at the launch site, and (iii) a model wind forecast valid at the launch site. The difference between the actual and anticipated fall points are shown in Fig. 7b. Using exact wind speeds leads to a positioning error of $0.47 \mathrm{~km}(6 \%)$. This error increases to $1.47 \mathrm{~km}(20 \%)$ when using a UHF wind profile and up to $1.58 \mathrm{~km}(22 \%)$ when a model forecast is used. The somewhat poor score obtained with the wind profiler data is a bit surprising, but is likely related to the low accuracy of wind profiler measurements under light wind conditions such as those encountered during BLLAST. Clearly, the accuracy of the horizontal wind profile used to simulate the flight trajectory is a key factor to properly estimate the location of the landing point. The residual error of $0.47 \mathrm{~km}$ 
(a) Ascent rate

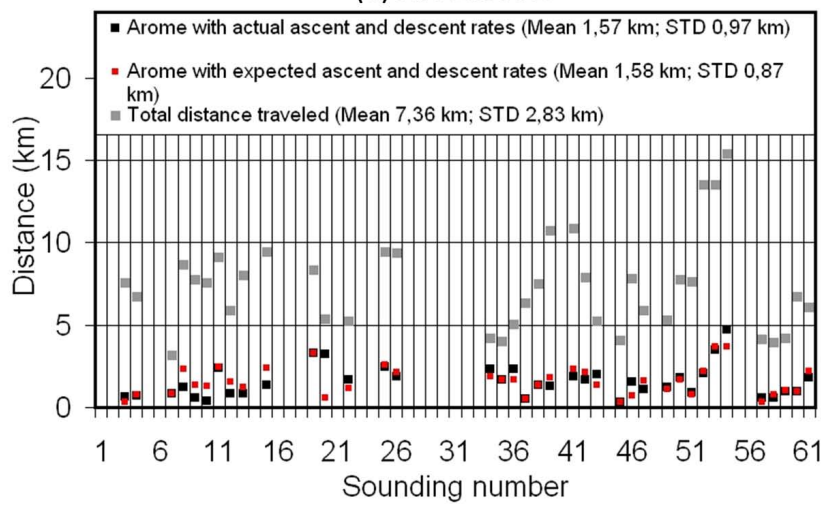

(b) Horizontal wind

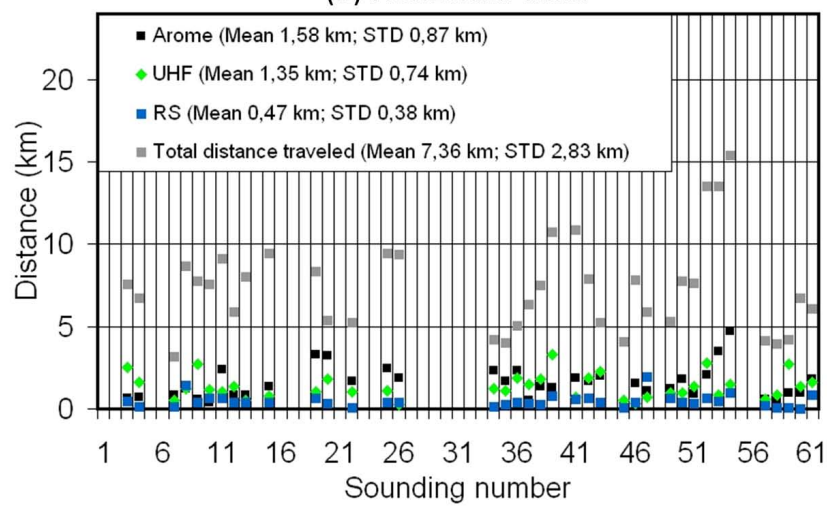

Fig. 7. Difference between actual and simulated radiosonde falling points as a function of (a) ascent rates and (b) horizontal wind profiles used to simulate the trajectories. Scores are computed for recovered balloons only.

$(6 \%)$ obtained with true horizontal wind values corresponds to the error arising from hypotheses made on mean vertical velocities.

A similar study could be performed to estimate the actual deviation of the carrier balloon separation point with respect to the expected/desired one. Although these statistics were not computed, one can roughly estimate this error to be about one-third of the one on the landing point. Considering ascent/descent speeds of respectively 5 and $3.4 \mathrm{~m} \mathrm{~s}^{-1}$, the horizontal distance travelled by the balloon during the ascent would be approximately two times less than that travelled during the descent (also see Sect. 4.2).

\subsection{Accuracy of the measurements}

Inadequate ventilation of the radiosonde can potentially have an impact on the accuracy of the measurement. This is more likely to occur at descent due to the slowest relative speed of the system $\left(3.4 \mathrm{~m} \mathrm{~s}^{-1}\right.$ vs. $\left.5 \mathrm{~m} \mathrm{~s}^{-1}\right)$. No significant difference between the ascent and descent phases could be seen in temperature measurements, but a few descending soundings showing instable humidity measurements were, how-
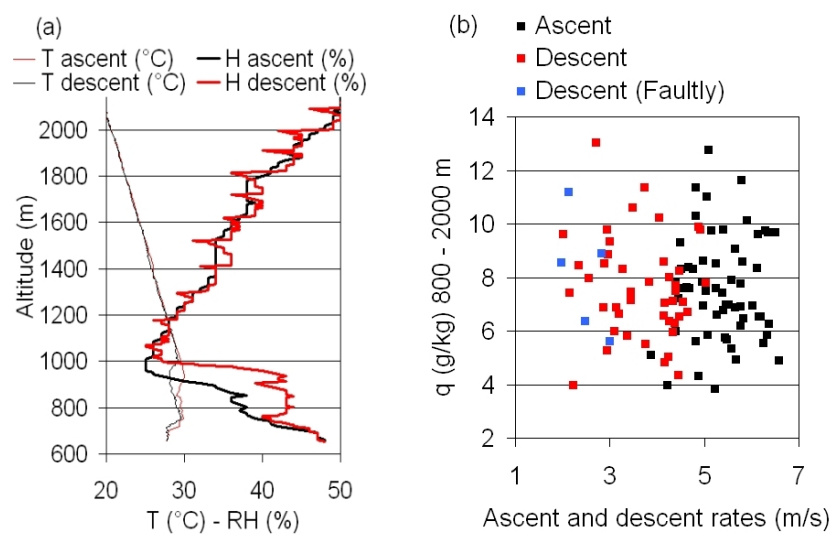

Fig. 8. Effect of insufficient ventilation on radiosonde measurements. (a) Example of disturbed sounding made during BLLAST on 26 June 2012, at 20:08 UTC. (b) Ascent and descent rates vs. mean specific humidity $\left(\mathrm{g} \mathrm{kg}^{-1}\right)$ between 800 and $2000 \mathrm{~m}$ for ascending soundings (black), descending soundings (red) and disturbed descending soundings (blue).

ever, identified. An example of such spurious humidity measurements is shown in Fig. 8a, which displays data collected in the layer $0.6-2 \mathrm{~km}$ during a descending sounding performed on 6 June 2011 around 20:00 UTC. One can note the presence of unrealistic peaks in humidity measurements, which seem to be regularly spaced along the vertical. The occurrences of these peaks are separated from a time period of $\sim 55 \mathrm{~s}$. These observations likely indicate a malfunctioning of the twin humidity sensor of Vaisala RS-92 radiosondes, which alternatively measure humidity over a cycle of $110 \mathrm{~s}$. This suggests that the probe ventilation was likely insufficient during this particular sounding.

After a careful review of all soundings performed during BLLAST, we found that this problem has actually occurred five times. This is illustrated in Fig. 8b, where blue dots correspond to the five soundings showing unrealistic humidity measurements. According to Fig. 8b, the problem always seems to occur at descent, and only when the mean descending speed of the radiosonde is lower than $3 \mathrm{~m} \mathrm{~s}^{-1}$. In order to mitigate this issue, one could think about using a lighter slowing balloon to increase the descent speed of the system - using a $50 \mathrm{~g}$ balloon would for instance increase the descending speed by about $20 \%$ with respect to the $100 \mathrm{~g}$ slowing balloons used in BLLAST and HyMeX. Using models proposed by Gallice et al. (2011) and Wang et al. (2009) to simulate the behaviour of sounding balloons in still air would also be useful to better control the ascent and descent rates of the balloon. 


\section{Test of the system during $\mathrm{HyMeX}$}

\subsection{The HyMeX field phase}

During BLLAST, this system was tested in relatively ideal conditions: light wind, clear skies and low release altitude, to name just a few. The $\mathrm{HyMeX}^{1}$ research programme provides another opportunity to evaluate the performance of this system in more complex, hostile meteorological situations. HyMeX aims at a better understanding and quantification of the hydrological cycle and related processes in the Mediterranean, with emphasis on high-impact weather events, interannual to decadal variability of the Mediterranean coupled system, and associated trends in the context of global change. In the framework of this project, a special observation period (SOP) was conducted in autumn 2012 to collect detailed observations of the coupled ocean-atmosphere system in various places of the NW Mediterranean Basin including southern France, Italy and Spain.

\subsection{Examples of dual-balloon soundings during $\mathrm{HyMeX}$}

Twelve dual-balloon soundings were performed in southern France during the HyMeX field campaign. The objectives of these soundings were twofold: (i) evaluate the thermodynamical properties of the low-to-mid-level flow originating from the Mediterranean Sea before it reaches the Massif Central mountains, and (ii) evaluate the possible modification experienced by this oceanic air mass during its propagation towards the higher terrain. To achieve those objectives, soundings were launched from the coastal town of Candillargues (Fig. 5), and the release pressure was set up so as to make the radiosonde fall as close as possible to the foothills of the Massif Central.

Figures 9 and 10 show vertical profiles of potential temperature and water vapour mixing ratio achieved by dualballoon soundings performed on 17 and 21 October 2012, respectively. Three-dimensional wind and reflectivity fields inferred from the analysis of multiple-Doppler radar data at times of soundings are also shown on each figure (the reader is referred to Bousquet and Tabary (2013) for details about the construction of these fields). On both days, a few soundings were launched from Candillargues at a $3 \mathrm{~h}$ interval. The separation was set to occur at $600 \mathrm{hPa}$, and the ascent and descent speeds were set to 5 and $3.4 \mathrm{~m} \mathrm{~s}^{-1}$, respectively. The points marking the locations of balloon separation and probe landing for each of the four flights are shown in Fig. 5. Note that the distance travelled by the probes during the ascending phase is approximately two times shorter than that flown during the descent phase, which is consistent with chosen ascent and descent rates of 5 and $3.4 \mathrm{~m} \mathrm{~s}^{-1}$.

On 17 October, the soundings were performed at 09:00 and 12:00 UTC. The total distance travelled by the ra-

\footnotetext{
${ }^{1}$ More information about this programme can be found at http: //www.hymex.org.
}

(a)

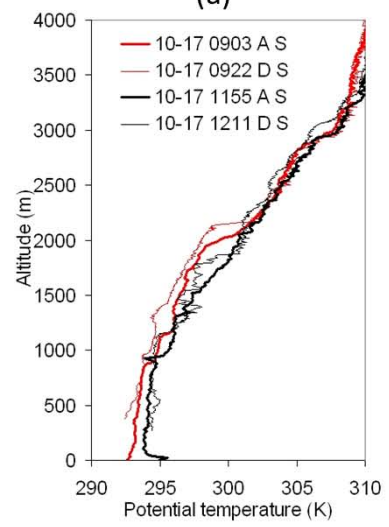

(c)

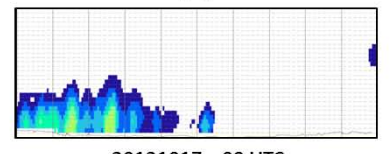

20121017-09 UTC

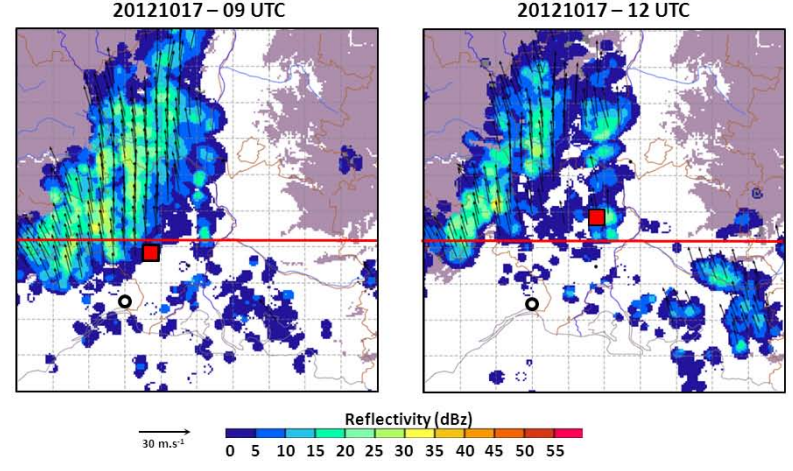

Fig. 9. Thermodynamical and precipitation data valid on 17 October 2012. Top panel: vertical profile of (a) potential temperature and (b) water vapour mixing ratio, derived from dual-balloon soundings at 09:00 (red) and 12:00 UTC (black). Thin (bold) lines correspond to ascending (descending) soundings. The locations of balloon separation (beginning of the downward sounding) are shown in Fig. 5. Bottom panel: horizontal ( $1.5 \mathrm{~km}$ a.m.s.l.) and vertical cross sections of radar reflectivity (dBZ) over a domain of $200 \mathrm{~km} \times 200 \mathrm{~km}$ (horizontal) $\times 14 \mathrm{~km}$ (vertical) centred on Nimes, valid at (c) 09:00 and (d) 12:00 UTC. The location of the cross section is indicated by the red line. The red square in $(\mathbf{c}, \mathbf{d})$ show the landing point of corresponding radiosoundings. Black vectors show the direction of the wind derived from multiple-Doppler analysis of radar data.

diosonde was $\sim 34 \mathrm{~km}$ for the first sounding and $\sim 48 \mathrm{~km}$ for the second one (Fig. 5). Both probes landed in cultivated areas at an altitude of $\sim 100 \mathrm{~m}$ a.m.s.l. and were easily recovered the same day. The distances travelled by the two radiosondes during the ascent phase were comparable, but were quite different during the descent phase. This indicates that the vertical wind field north of the balloon separation point experienced significant changes between the two launches. No precipitation was present along the coast at launching times, but weak orographic precipitation extending 
(a)

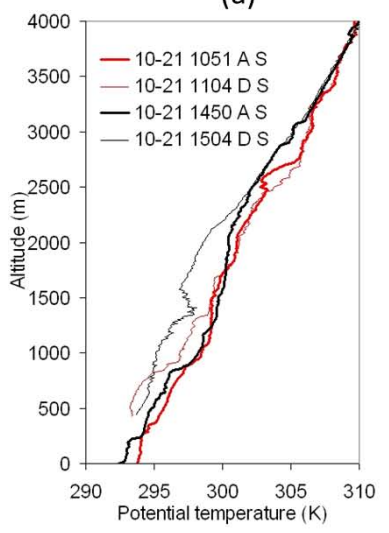

(c)

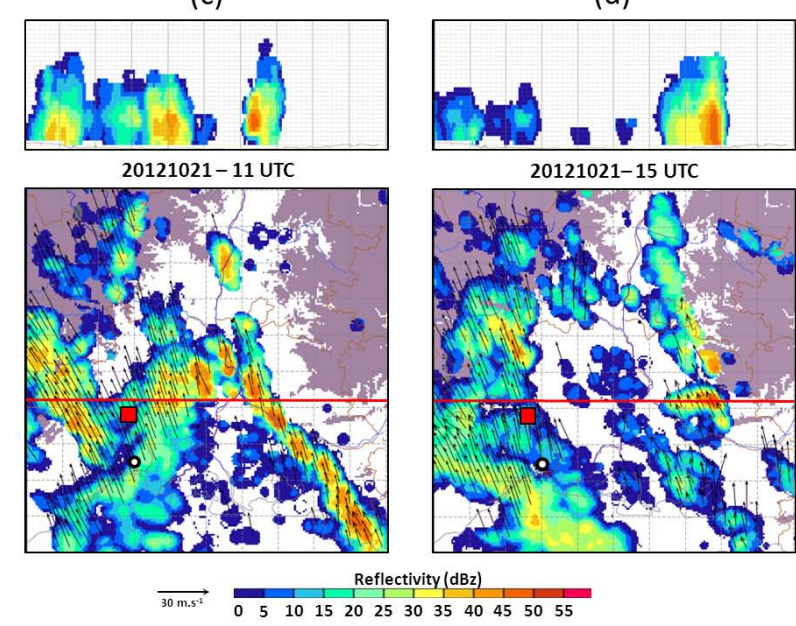

Fig. 10. As in Fig. 9, but for the 21 October 2012 at 12:00 and 15:00 UTC.

up to a height of $6 \mathrm{~km}$ could be observed over the terrain at both times (Fig. 9c, d).

The potential temperature at the coast increased by a couple of $\mathrm{K}$ within most of the measured layer (Fig. 9a) during the $3 \mathrm{~h}$ period separating the two launches. The mixing ratio remained comparable except between 1 and $2 \mathrm{~km}$ a.m.s.l., where it decreased from up to $3 \mathrm{~g} \mathrm{~kg}^{-1}$ (Fig. 9b). The lowlevel moisture was somewhat moderate, with mixing ratio values of $\sim 11 \mathrm{~g} \mathrm{~kg}^{-1}$, which is consistent with the lack of heavy precipitation over the terrain. The thermodynamical properties of the incoming southerly flow measured farther inland at 09:00 and 12:00 UTC were similar to those observed at the coast at the same times. One can notice small temperature variations of up to $0.5 \mathrm{~K}$ at 09:00 and 12:00 UTC, as well as moderate moisture increase between 1 and $2 \mathrm{~km}$ a.m.s.l. at 09:00 UTC, but the air mass clearly did not experience significant modifications between the coast and the foothills of the Massif Central.

On 21 October, two other dual-balloon soundings were performed at 12:00 and 15:00 UTC. This time, radar observations indicate the presence of convective precipitation over the terrain extending up to a height of $10 \mathrm{~km}$ (Fig. 10c, d). The two radiosondes landed in the same area after a flight of $\sim 35 \mathrm{~km}$ (Fig. 5). The proximity of the two landing points indicates that the wind field over the area was quite uniform within the $3 \mathrm{~h}$ period separating the two launches. Also note that the actual landing point of the radiosonde launched at 15:00 UTC is actually very close to the one simulated before using an Arome forecast (red trajectory).

The potential temperature profiles measured near the coast at 12:00 and 15:00 UTC (Fig. 10a) were extremely similar and did not evolve significantly during this period. Mixing ratio profiles (Fig. 10b), however, indicate significant fluctuations of the moisture content within the boundary layer. Mixing ratio values increased from $\sim 2 \mathrm{~g} \mathrm{~kg}^{-1}$ in $3 \mathrm{~h}$ close to the surface, but decreased significantly between 500 and $2500 \mathrm{~m}$ a.m.s.l. Also notice that the moisture at low levels was more abundant than on 17 October (Fig. 9b), which may explain the more convective nature of precipitation over the terrain (Fig. 10c, d). Changes that occurred in theta and mixing ratio profiles between the coast and the foothills of the terrain also show contrasting behaviour. The vertical structure of the mixing ratio is almost identical at both times, except around $1 \mathrm{~km}$ a.m.s.l., where one can notice a slight increase of the moisture content. The temperature profile, on the other hand, decreases significantly within the boundary layer (with variations of up to $3 \mathrm{~K}$ at 15:00 UTC), which suggest that the low-level flow experienced important modifications while propagating towards the higher terrain. Although it is not possible to figure out precisely what factors are responsible for the observed changes, the latter are also likely related to precipitation and convection processes. This may include convergence and divergence, respectively, due to the overturning circulation associated with convection, as well as condensation or evaporation of precipitation, among others.

In addition to performing conventional temperature and humidity measurements, the dual-balloon system was also used in HyMeX to test a prototype of a new probe called LOAC (Light Optical Aerosol Counter). LOAC is a new generation of aerosol counter that has been developed in cooperation between the company MeteoModem and several French scientific laboratories. It consists in a small optical particle counter/sizer of $\sim 250 \mathrm{~g}$ that performs measurements at scattering angles of $12^{\circ}$ and $60^{\circ}$. It is used to determine the aerosol particle concentrations in 20 size classes within a diameter range of $0.3-100 \mu \mathrm{m}$. The ratio of the measurements at the two angles is used to discriminate between the different types of aerosol particles in the different size classes (i.e. wet and liquid particles, soil dust and soot). LOAC is designed to be deployed under all kinds of atmospheric balloons. A prototype, specially developed for free balloon deployment, was tested for the first time during HyMeX.

A test flight was conducted from Candillargues on 23 September 2012 between 09:00 and 09:45 UTC under clear sky conditions. The goal was to evaluate the performance of this new sensor against backscattering lidar 

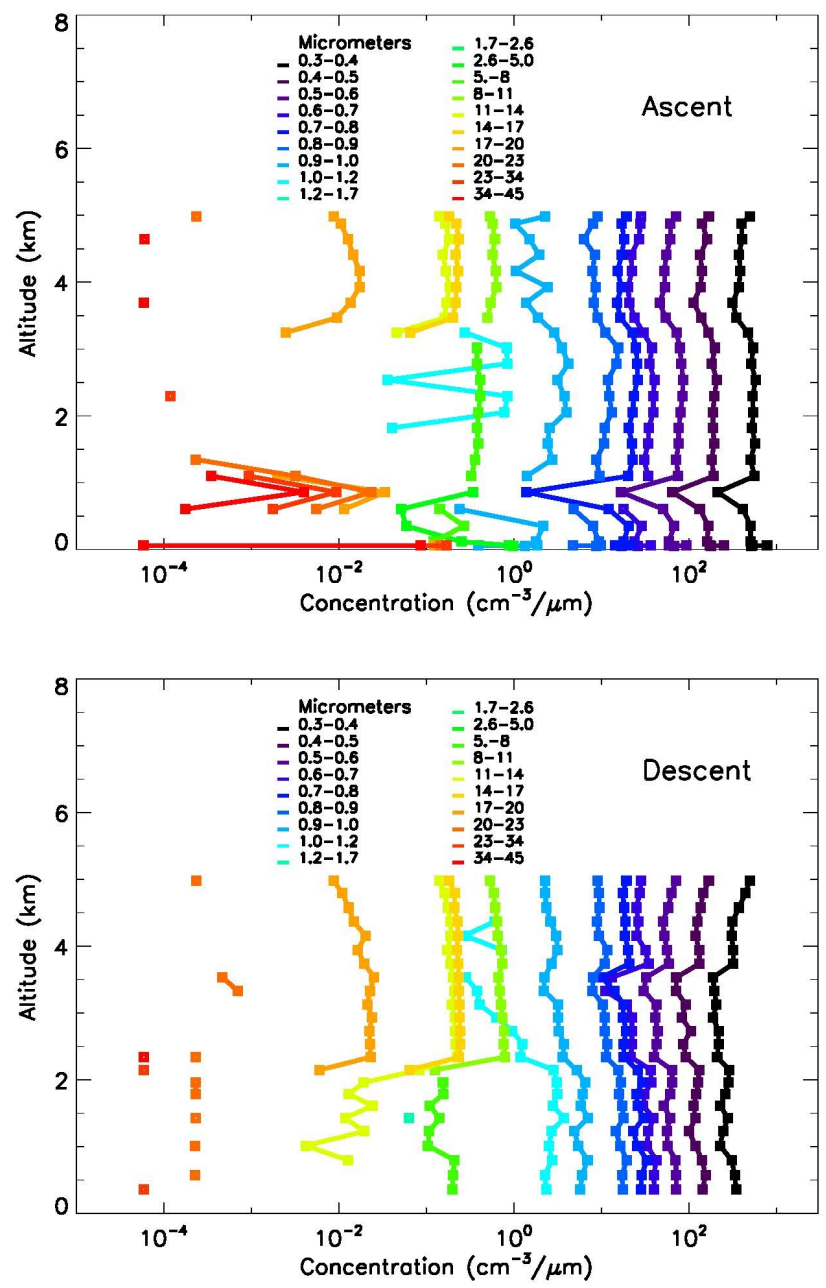

Fig. 11. Vertical profiles of aerosol concentration as a function of particle size inferred from the LOAC probe between 09:00 and 09:45 UTC on 23 September 2012. Upper (lower) panel shows data collected during the ascending (descending) phase of the sounding.

measurements collected at the same location during the HyMeX field phase. The possibility to recover the instrumentation was an important consideration since this prototype of LOAC was unique and quite expensive (several thousands of euros). The balloon release pressure was set to $500 \mathrm{HPa}$, and light winds were present within the entire troposphere. The prototype sensor was recovered in good condition about $20 \mathrm{~km}$ away from the launching point.

Examples of aerosol measurements performed during the ascending and descending phases are shown in Fig. 11. The most interesting feature is an aerosol enhancement detected above $3 \mathrm{~km}$ during ascent and above $2.5 \mathrm{~km}$ during descent. LOAC indicates that such aerosols are solid, which suggests remnants of a Saharan sand transport episode that was detected above southern France during this period. It can also be noticed that the small haze layer observed at around $1 \mathrm{~km}$ altitude during ascent is not present during the descent a few tens of km away.

\section{Conclusions and perspectives}

A new system for high-frequency atmospheric profiling based upon radiosondes and free balloons was tested during the field phases of BLLAST and HyMeX. This dual-balloon sounding system is very versatile, and could be deployed in all field projects that require the use of radiosoundings. The standard system consists of a conventional Vaisala receiver and a GPS radiosonde (pressure, wind, humidity and temperature), and that is tied to a couple of inflated balloons. The principle of the sounding system is to permit the first balloon to detach from the rawinsonde at a predetermined altitude, allowing for the rawinsonde to slowly descend with the second balloon so as to perform a second, new sounding. The instrumentation is then eventually recovered. The expecting landing area is anticipated before the flight by estimating the trajectory of the probe using a forecasted or observed wind profile, and by specifying both the balloon release altitude and the expected mean ascent and descent rates of the system. The real landing point is determined by the last transmission of the radiosonde GPS and the visual landmark provided by the second balloon.

Around 60 soundings were performed in light wind conditions during the BLLAST field phase. The radiosonde recovery rate reached more than $80 \%$, and the release mechanism performed well about $84 \%$ of the time. Recovered radiosondes were generally reused several times, often immediately after recovery. A total of 114 vertical profiles were obtained by using only nine radiosondes, which demonstrates the high potential and cost effectiveness of this system.

A posteriori experiments conducted after the BLLAST field phase reveal that a proper estimation of the horizontal wind profile is key in order to accurately assess the landing location of the probe. The accuracy of the vertical speed used to simulate the trajectory of the probe was found to have a more limited impact with an error of approximately $6 \%$ of the total distance travelled by the balloon that corresponds to the fluctuation of the vertical speed with height.

Additional tests were also performed under more severe weather conditions during the field phase of the HyMeX project. In particular, the dual-balloon system was used to describe the modifications possibly experienced by an air mass propagating from the Mediterranean coast towards the foothills of the Massif Central mountains, located about $40 \mathrm{~km}$ to the north. The analysis of the soundings performed on 17 and 21 October shows that this system can be easily set up to sample precise areas and monitor the space and/or time variability of given atmospheric parameters. The system was also used to test and recover the prototype of a new aerosol counter designed to be used under free balloons. Overall, soundings performed during HyMeX have demon- 
strated the good reliability of the system in all-weather situations as well as its value in retrieving expensive probes or prototype sensors.

Although results presented in this paper are promising, a number of enhancements are still needed to improve the robustness and accuracy of this system. Accurate prediction of the balloon trajectory is, for instance, important to achieve the desired pressure level, separation and landing point, and is critical in order for the researcher to decide whether the system can achieve its scientific goals. A potential way to improve the simulated trajectory of the flight would be to take more precisely into account the behaviour of the balloons in still air following, for instance, findings of Gallice et al. (2011) or Wang et al. (2009). One could also think about using observed (e.g. Bousquet and Tabary, 2013) or forecasted 3-D wind fields instead of using a 1-D vertical wind profile at the launching point, updating the trajectory in real-time using in situ measurements provided by the radiosonde, or remotely triggering the separation of the carrier balloon, among other ideas. Improvements are also needed to increase the reliability of the system and the accuracy of measurements. For instance, the release mechanism should be tested and possibly adapted to properly function at altitudes higher than 6-7 km, where the temperature starts to become very cold. Finally, one should also think of a way to ensure proper ventilation of the system at descent to avoid potentially spurious measurements when performing classical atmospheric radiosoundings. As stated before, a possibility would be to increase the descent speed of the radiosonde through use of lighter slowing balloons, but other options are likely possible. In order to reach those goals, as well as make it more robust, the system will be made freely available to the community. Detailed system specifications, software and assembly diagrams will be graciously provided upon request to the authors.

Acknowledgements. This work has been sponsored by the MISTRALS/HyMeX programme. The authors are grateful to the reviewers for their pertaining remarks and careful reading of the manuscript.

Edited by: D. Cimini

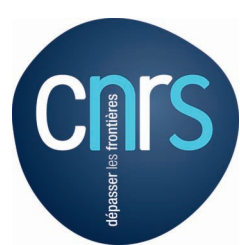

The publication of this article is financed by CNRS-INSU.

\section{References}

Bousquet, O. and Tabary, P.: Development of a nationwide, realTime, 3-D wind and reflectivity radar composite in France, Q. J. Roy. Meteorol. Soc., doi:10.1002/qj.2163, in press, 2013.

Douglas, M. W.: Progress towards development of the glidersonde: a recoverable radiosonde system, Technical Conference on Meteorological and Environmental Instruments and Methods of Observation, St. Petersburg, Russian Federation, 27-29 November 2008, P1.6, 2008.

Ducrocq, V., Braud, I., Davolio, S., et al.: The HyMeX Special Observing Period, B. Am. Meteorol. Soc., accepted, 2013.

Gallice, A., Wienhold, F. G., Hoyle, C. R., Immler, F., and Peter, T.: Modeling the ascent of sounding balloons: derivation of the vertical air motion, Atmos. Meas. Tech., 4, 2235-2253, doi:10.5194/amt-4-2235-2011, 2011.

Meisinger, L.: Recovery of sounding balloons at sea, Mon. Weather Rev., 49, p. 158, 1921.

Lothon, M., Lohou, F., Durand, P., et al.: The Boundary-Layer Late Afternoon and Sunset Turbulence field experiment, Proceedings, 20th Symposium on Boundary-Layers and Turbulence, Boston, USA, 9-13 July 2012, 14 B1, 2012.

Seity, Y., Brousseau, P., Malardel, S., Hello, G., Bénard, P., Bouttier, F., Lac, C., and Masson, V.: The AROME-France ConvectiveScale Operational Model, Mon. Weather Rev., 139, 976-991, 2011.

Tennermann, J., Helenelund, C., and Quire, C.: A Novel Method for Measuring Carbon Dioxide Concentration From 0 to 2.5 Kilometers Above the Ground, AGU Fall Meeting, San Francisco, USA, 13-17 December, 2004, B43C-03, 2004.

Wang, J., Bian, J., Brown, W. O., Cole, H., Grubišić, V., and Young, K.: Vertical air motion from T-REX radiosonde and dropsonde data, J. Atmos. Ocean. Technol., 26, 928-942, 2009. 